\title{
Spreading pattern and CT findings of very early-stage peripheral small-cell lung cancer
}

\author{
Takeshi Terashima ${ }^{1 \#}$, Tatsu Matsuzaki ${ }^{1}$, Shotaro Chubachi ${ }^{1}$, Fumio Sakamaki $^{2}$, Minako Satoh ${ }^{1}$, \\ Eri Tomioka $^{1}$, George Horio ${ }^{1}$, Rika Ogawa ${ }^{1}$, Asuka Naitoh $^{1}$, Hiroya Ojiri ${ }^{3}$ \\ ${ }^{1}$ Department of Respiratory Medicine, Tokyo Dental College Ichikawa General Hospital, Ichikawa, Japan; \\ \#Corresponding Author: terasima@tdc.ac.jp \\ ${ }^{2}$ Department of Respiratory Medicine, Tokyo Saiseikai Central Hospital, Tokyo, Japan \\ ${ }^{3}$ Department of Radiology, Tokyo Dental College Ichikawa General Hospital, Ichikawa, Japan
}

Received 9 September 2013; revised 8 October 2013; accepted 16 October 2013

Copyright (c) 2013 Takeshi Terashima et al. This is an open access article distributed under the Creative Commons Attribution License, which permits unrestricted use, distribution, and reproduction in any medium, provided the original work is properly cited.

\section{ABSTRACT}

Chest CT frequently reveals small pulmonary lesions. If there is no associated hilar or mediastinal lymphadenopathy, small-cell lung cancer (SCLC) is considered to be very early-stage. Few studies, however, have described the characteristic CT findings of very early-stage SCLC. Clarifying these findings would reduce diagnostic delay. The purpose of this study was to determine the characteristic CT findings of very earlystage SCLC. Computed tomography images obtained from 547 consecutive patients with lung cancer between 2003 and 2012 at Tokyo Dental College Ichikawa General Hospital were reviewed retrospectively. One hundred of these patients had SCLC and 447 had non-SCLC (NSCLC). These CT images, along with any that had also been obtained prior to the one on which the final diagnosis was based, were reviewed. In 5 of the cases reviewed, specific findings and a characteristic spreading pattern were identified on CT images that might have allowed a diagnosis of SCLC to have been made sooner. The findings included a sub-pleural, small nodule accompanied by daughter nodules spreading longitudinally along the bronchovascular bundle, no air bronchogram or cavitation, and background emphysematous change. These were not identified on CT images of very earlystage NCSLC, however $(n=22)$. Awareness of the relevance of these findings would help physicians and radiologists arrive at a differential

\footnotetext{
*Financial/nonfinancial disclosures: The authors declare no potential conflict of interest with any company or organization whose products or services may have been mentioned in this article.
}

diagnosis of small pulmonary nodules.

Keywords: SCLC; Small Pulmonary Nodules; Beaded Appearance; Bronchovascular Bundle; CT Scan

\section{INTRODUCTION}

Small-cell lung cancer (SCLC) usually grows very rapidly. The majority of SCLC patients are symptomatic at first visit to a hospital, and extended disease (ED) with distant metastases is diagnosed in two thirds of these cases. The prognosis for limited disease (LD)-SCLC treated with the standard combination of chemotherapy and radiation is better than that for ED-SCLC. If there is no associated hilar or mediastinal lymphadenopathy in LD-SCLC, it is usually designated as "very early-stage" [1]. This type of peripheral, very early-stage SCLC has a good prognosis when treated with surgery followed by chemotherapy, although some uncertainly remains as to if and when the surgical component best fits into the treatment modality [2-4]. The earlier the disease is diagnosed, the more successful treatment is likely to be. Therefore, knowing the radiological characteristics of very early-stage SCLC is crucial in reducing diagnostic delay.

The recent increase in the clinical application of thoracic computed tomography (CT) has led to a marked rise in incidental detection of small peripheral pulmonary nodules. A set of guidelines has been established to help physicians in the management of such nodules [5-11]. These guidelines, however, contain very little information on the characteristic CT imaging features of very early-stage SCLC.

The purpose of this study was to determine the characteristic CT findings of very early-stage SCLC by re- 
viewing CT images, including those obtained prior to diagnosis of the disease. We believe that such information would prove invaluable in the early diagnosis of this disease, including from CT scans initially aimed at a wide range of other diseases.

\section{MATERIALS AND METHODS}

Computed tomography images obtained from 547 consecutive patients with lung cancer between 2003 and 2012 at Tokyo Dental College Ichikawa General Hospital were reviewed retrospectively. Patients with SCLC ( $n=$ 100) included 86 men and 14 women (30 - 91 years old; mean age, 69.7 years; LD/ED, 31/69). Patients with nonSCLC (NSCLC) $(n=447)$ included 338 men and 109 women (34-92 years old; mean age, 69.7 years; stage IA/ IB/IIA/IIB/IIIA/IIIB/IV, 43/29/8/14/49/103/201, respectively). When available, earlier CT images obtained prior to that on which final diagnosis of lung cancer was made were also examined. A 64- or 16-row, multi-slice, helical CT scanner (Brilliance 64, Philips, Medical Systems, Cleveland, Ohio; and Mx-8000 IDT, Philips, Medical Systems, respectively) was used. The images obtained were reviewed by two radiologists. The study protocol was approved by the Ethics Committee of our institute.

\section{RESULTS}

We identified 5 and 22 cases in which CT scans obtained prior to that on which a diagnosis was made might have allowed an earlier diagnosis of SCLC and NSCLC, respectively. The clinical features of the 5 cases with SCLC are listed in Table 1. All were current or past smokers.

Case 1. The initial chest CT scans in May 2005 revealed a tiny nodule in the right upper lobe (Figures 1(a) and (b)). Proximal to this nodule was another, ovoid nodule measuring $5 \mathrm{~mm} \times 3 \mathrm{~mm}$ distributed along the bronchovascular bundle (Figures 1(b) and (c)). They were misclassified as inflammatory scars by radiologist. Another set of CT images obtained at one year later, in May 2006, demonstrated that the irregularly-shaped, tiny nodule had grown to $10 \mathrm{~mm} \times 10 \mathrm{~mm}$ in size (Figure 1(d)), and that it was accompanied by another polyhedral, elliptical nodule measuring $13 \mathrm{~mm} \times 26 \mathrm{~mm}$ (Figures 1(d) and (e)). A positron emission tomography (PET)-CT scan demonstrated increased uptake of fluorodeoxyglucose (FDG) in both the peripheral nodule and elliptical lesion. Cytological examination of transbronchial brushings indicated SCLC.

Case 2. Chest CT scans obtained in July 2009 revealed an irregularly-shaped, lobulated nodule with a polyhedral margin in the right middle lobe (Figure 2(h)). The sub-pleural nodule was accompanied by a well-demarcated, polyhedral, lobulated nodule (Figures 2(e)-(g)).
Table 1. Clinical features of 5 cases.

\begin{tabular}{|c|c|c|c|c|c|}
\hline No & $\begin{array}{l}\text { Age } \\
\text { Sex }\end{array}$ & $\begin{array}{c}\text { Smoking } \\
\text { Packs } \\
\text { per-year }\end{array}$ & Symptoms & $\begin{array}{l}\text { Stage at } \\
\text { diagnosis }\end{array}$ & $\begin{array}{l}\text { Medical } \\
\text { history }\end{array}$ \\
\hline 1 & $\begin{array}{c}65 \\
\text { Male }\end{array}$ & 40 & $(-)$ & $\begin{array}{c}\text { IIIA } \\
\text { T3N1M0 }\end{array}$ & $\begin{array}{l}\text { Bile duct } \\
\text { cancer }\end{array}$ \\
\hline 2 & $\begin{array}{c}74 \\
\text { Male }\end{array}$ & 50 & $\begin{array}{l}\text { Productive } \\
\text { cough }\end{array}$ & $\begin{array}{c}\text { IIIA } \\
\text { T2N2M0 }\end{array}$ & Post CABG \\
\hline 3 & $\begin{array}{c}79 \\
\text { Female }\end{array}$ & 36 & $(-)$ & $\begin{array}{c}\text { IIIA } \\
\text { T1N2M0 }\end{array}$ & Post CABG \\
\hline 4 & $\begin{array}{c}65 \\
\text { Male }\end{array}$ & 40 & $(-)$ & $\begin{array}{c}\text { IIIA } \\
\text { T2N2M0 }\end{array}$ & BPH \\
\hline 5 & $\begin{array}{c}65 \\
\text { Male }\end{array}$ & 94 & $\begin{array}{l}\text { Peripheral neuropathy } \\
\text { Diplopia }\end{array}$ & $\begin{array}{c}\text { IIB } \\
\text { T3N0M0 }\end{array}$ & Skin cancer \\
\hline
\end{tabular}

$\mathrm{CABG}=$ coronary artery bypass graft; $\mathrm{BPH}$ = benign prostatic hypertrophy.

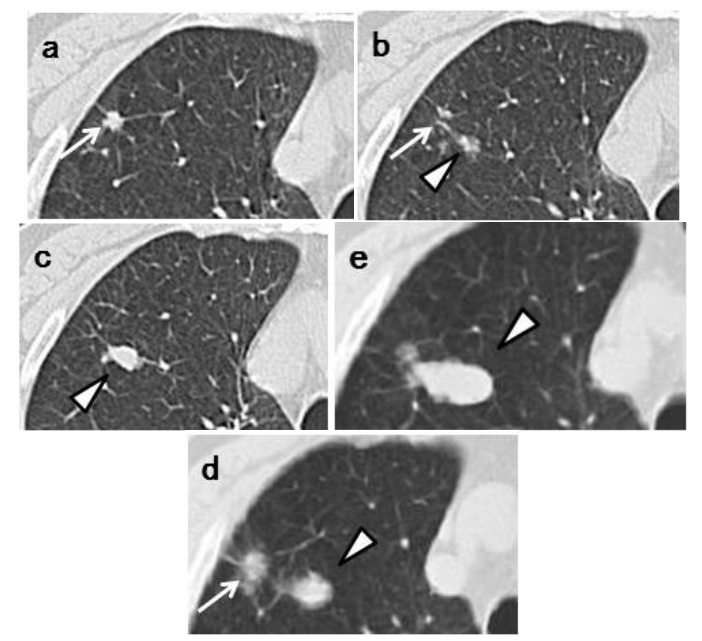

Figure 1. Initial chest CT scans in May 2005 revealed irregularly-shaped, tiny nodule with spiculation (arrow) measuring $3 \mathrm{~mm} \times 3 \mathrm{~mm}$ in periphery of right upper lobe (a, b). Another ovoid nodule (arrowhead) proximal to it measuring $5 \mathrm{~mm} \times 3 \mathrm{~mm}$ was distributed along bronchovascular bundle (b, c). Repeat CT scan at one year later in May 2006 revealed lesion, now measuring $10 \mathrm{~mm} \times 10$ $\mathrm{mm}$, had reached nodule (arrow)(d); this lesion was accompanied by polyhedral elliptical nodule (arrowhead) measuring $13 \mathrm{~mm} \times 26 \mathrm{~mm}(\mathrm{~d}, \mathrm{e})$.

Coronary CT scans in September 2008 showed a small nodule with a scalloped boarder (Figure 2(d)) accompanied by three well-defined, round nodules, ranging in size from $2 \mathrm{~mm}$ to $6 \mathrm{~mm}$ (Figures 2(a)-(c)). A PET-CT scan in October 2009 demonstrated increased uptake of FDG in the peripheral nodules and the right hilar and mediastinal lymph nodes. Bronchoscopy and cytological examination of bronchial washings indicated SCLC.

Case 3. Chest CT scans obtained in July 2011 revealed a nodule with a polyhedral margin in the left lower lobe (Figures 3(d) and (e)). The peripheral nodule was connected to another nodule which was distributed along the bronchovascular bundle (Figures 3(d)-(f)). Enhanced CT 

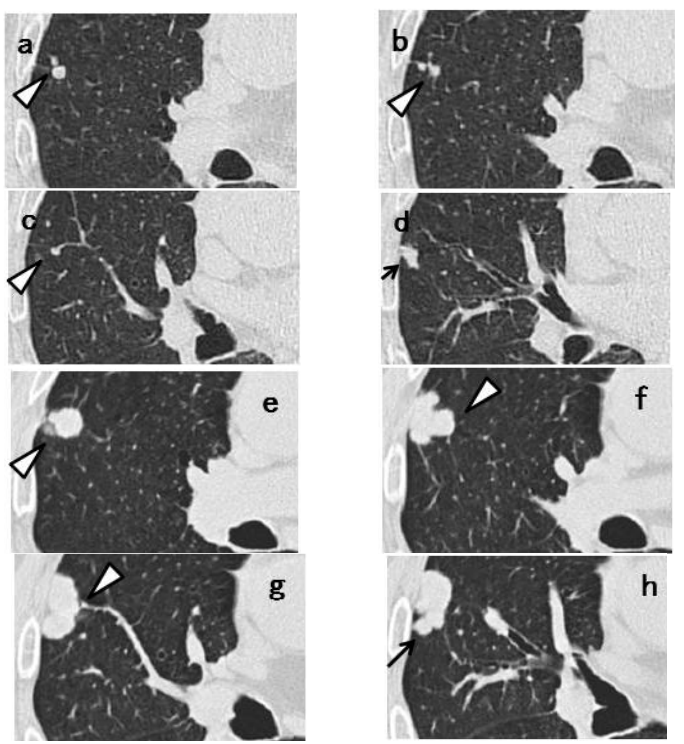

Figure 2. Irregularly-shaped, small nodule measureing $11 \mathrm{~mm} \times 6 \mathrm{~mm}$ (arrow) observed retrospectively on coronary CT scan in September 2008 (d). Subpleural nodule in right middle lobe was accompanied by three of well-defined, round nodules ranging in size from $2 \mathrm{~mm}$ to $6 \mathrm{~mm}$ (arrowhead) (a-c). CT scans in July 2009 revealed that sub-pleural nodule had increased to irregularly-shaped, lobulated mass measuring $27 \mathrm{~mm} \times 12 \mathrm{~mm}$ with polyhedral margin (arrow) (h). Accompanying nodules developed into one, well-defined polyhedral lobulated nodule (e-g).
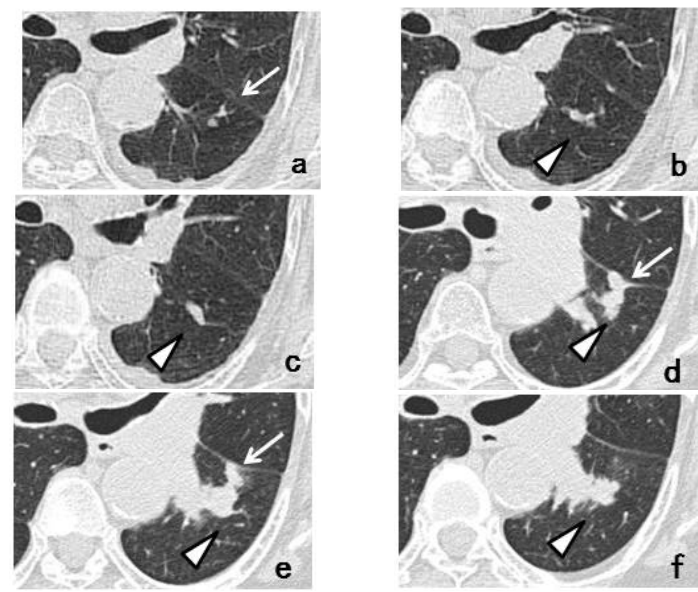

Figure 3. A tiny nodule measuring $3 \mathrm{~mm} \times 3 \mathrm{~mm}$ (arrow) observed retrospectively on coronary CT scan in April 2010 (a). Tiny nodule was located close to inter-lobular pleura in left lower lobe, accompanied by well-demarcated, ovoid nodule (arrowhead) measuring $11 \mathrm{~mm} \times 4 \mathrm{~mm}$ distributed along bronchovascular bundle (b, c). CT scans in July 2011 revealed irregularly-shaped, lobulated nodule measuring $11 \mathrm{~mm} \times 6 \mathrm{~mm}$ with polyhedral margin adjacent to inter-lobular pleura in left lower lobe $(d, e)$. Nodule was connected to accompanying nodule (arrowhead) which grew along bronchovascular bundle and measured $13 \mathrm{~mm} \times 12 \mathrm{~mm}(\mathrm{~d}-\mathrm{f})$. scans showed left hilar and mediastinal lymph node metastases. Coronary CT scans performed in April 2010 showed a tiny nodule in the left lower lobe (Figure 3(a)). The peripheral nodule was accompanied by an ovoid nodule (Figures 3(b) and (c)). Cytological examination of bronchial brushings indicated SCLC.

Case 4. Chest CT scans obtained in March 2012 revealed an irregularly-shaped, lobulated, expansive mass measuring $55 \mathrm{~mm} \times 50 \mathrm{~mm}$ in the left lingular lobe, accompanied by left hilar and mediastinal lymph node metastases (Figure 4(c)). Earlier CT scans obtained in March 2011 had revealed a nodule measuring $13 \mathrm{~mm} \times$ $12 \mathrm{~mm}$. This nodule was observed adjacent to the interlobular pleura together with pleural indentation and connected to three other nodules (Figures 4(a) and (b)). The initial diagnosis by two radiologists was organized pneumonia. Bronchoscopy and bronchial washings for cytology indicated SCLC.

Case 5. Chest CT scans obtained in January 2012 revealed a small nodule adjacent to the right pleura of the upper lobe (Figure 5(a)). The sub-pleural nodule was accompanied by another smaller nodule (Figure 5(b)). Follow-up CT scans in June 2012 showed growth of the lesions (Figures 5(c) and (d)). A PET-CT scan performed in July 2012 demonstrated increased uptake of FDG in both nodules. Percutaneous, fine-needle, aspiration biopsy guided by CT revealed SCLC.

In all 5 cases, scattered, low-density areas were observed on the CT scans, suggesting emphysematous lung tissue. Earlier CT scans had shown primary nodules ranging in size from $3 \mathrm{~mm}$ to $13 \mathrm{~mm}$ located in the subpleural lesion together with pleural indentation. They had not shown, however, any apparent lymph-node or distant metastases. The CT findings in these 5 cases are listed in

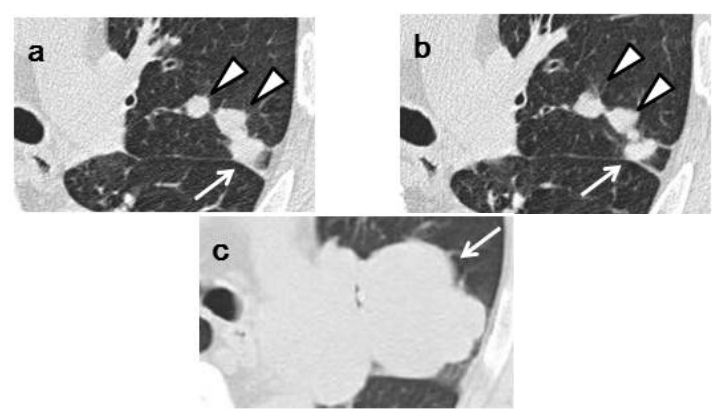

Figure 4. Initial CT scans in March 2011 had shown well-demarcated nodule (arrow) measuring $13 \mathrm{~mm} \times$ $12 \mathrm{~mm}$. Nodule was adjacent to inter-lobular pleura of left lingular lobe and had pleural indentation (a, b). Nodule was connected to three accompanying nodules (arrowhead) ranging in size from $3 \mathrm{~mm}$ to 14 $\mathrm{mm}$ which were distributed along bronchovascular bundle (a, b). CT scans in March 2012 revealed that sub-pleural nodule had joined with accompanying nodules, increasing in mass and measuring $55 \mathrm{~mm} \times$ $50 \mathrm{~mm}$ (arrow) (c). 

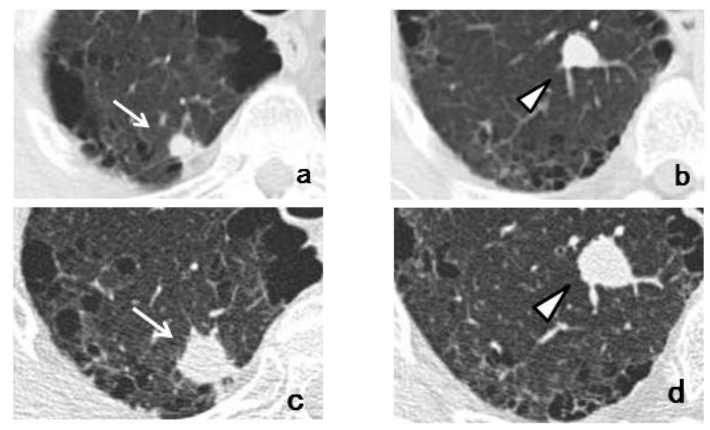

Figure 5. Initial CT scans in January 2012 had shown well-demarcated, small, round nodule (arrow) measuring $8 \mathrm{~mm} \times 7 \mathrm{~mm}$ adjacent to right pleura of upper lobe (a). Sub-pleural nodule was accompanied by well-demarcated, small nodule (arrowhead) measuring $14 \mathrm{~mm} \times 12 \mathrm{~mm}$ distributed along bronchovascular bundle (b). Repeat CT scan in June 2012 revealed that size of sub-pleural nodule (arrow) had increased to 18 $\mathrm{mm} \times 14 \mathrm{~mm}(\mathrm{c})$, while accompanying nodule (arrowhead) had grown to $18 \mathrm{~mm} \times 15 \mathrm{~mm}(\mathrm{~d})$.

Table 2. The nodules were solid and irregularly-shaped, with no air bronchogram or cavitation. They were either spiculated (Cases 1 and 5) or had a scalloped border (Cases 2, 3 and 4). Each was accompanied by small nodules which were distributed along the bronchovascular bundle. Doubling time ranged from 54 to 81 days (average, 71 days). The characteristic CT findings are summarized in Table 3 . These characteristic findings were not identified on CT images which had been obtained prior to the final diagnosis of NCSLC $(n=22)$.

\section{DISCUSSION}

This study had two major findings: the identification of a well-defined spreading pattern and several characteristic CT findings in very early-stage SCLC. A small nodule together with daughter nodules spreading longitudinally along the bronchovascular bundle was identified. The primary and daughter lesions had the appearance of beads, suggesting a diagnosis of SCLC. It should be emphasized that the characteristics shown in Table 3 are usually considered to indicate a benign lesion. A number of studies have investigated discrimination of benign from malignant pulmonary nodules. The probability of non-calcified, solid nodules of less than $5 \mathrm{~mm}$ in diameter being malignant was reported to be very low $[6,8,10,11]$. Air bronchograms were seen more commonly in malignant than in benign nodules [9]. According to the Fleischner Guidelines, features such as clustering of multiple nodules in a single location in the lung tend to favor an infectious process [8]. The presence of adjacent tiny nodules, called satellite nodules, has been reported to be strongly associated with benignity [9]. The results of the present study revealed a sub-pleural, solid nodule accompanied by tiny satellite nodules but no air
Table 2. CT findings of 5 cases.

\begin{tabular}{|c|c|c|c|c|}
\hline No & Location & & Prior CT & $\begin{array}{c}\mathrm{CT} \text { at } \\
\text { diagnosis }\end{array}$ \\
\hline & & $\begin{array}{l}\text { Size } \\
(\mathrm{mm})\end{array}$ & Characteristics & Size (mm) \\
\hline 1) & RUL & $3 \times 3$ & $\begin{array}{l}\text { An irregularly-shaped, tiny nodule } \\
\text { with an ovoid nodule proximal to it }\end{array}$ & $10 \times 10$ \\
\hline 2) & RML & $11 \times 6$ & $\begin{array}{c}\text { An irregularly-shaped, small } \\
\text { nodule with } 3 \text { accompanying } \\
\text { well-demarcated, round nodules }\end{array}$ & $27 \times 12$ \\
\hline 3) & LLL & $3 \times 3$ & $\begin{array}{l}\text { An irregularly-shaped, tiny } \\
\text { nodule with a well-demarcated, } \\
\text { ovoid nodule proximal to it }\end{array}$ & $11 \times 6$ \\
\hline 4) & LUL & $13 \times 12$ & $\begin{array}{l}\text { A nodule with pleural indentation } \\
\text { connected to } 3 \text { accompanying } \\
\text { nodules distributed along the } \\
\text { bronchovascular bundle }\end{array}$ & $55 \times 50$ \\
\hline 5) & RUL & $8 \times 7$ & $\begin{array}{l}\text { A well-demarcated, small nodule } \\
\text { accompanied by a } \\
\text { well-demarcated nodule along the } \\
\text { bronchovascular bundle }\end{array}$ & $18 \times 14$ \\
\hline
\end{tabular}

RUL = right upper lobe; $\mathrm{RML}$ = right middle lobe; $\mathrm{LLL}=$ left lower lobe; LUL = left upper lobe.

Table 3. Characteristics CT findings of very early SCLC.

\begin{tabular}{lc}
\hline 1) & Solid nodule \\
2) & Irregularly-shaped nodule \\
$3)$ & Well-demarcated margin \\
$4)$ & Size could be less than $5 \mathrm{~mm}$ \\
$5)$ & No air bronchogram \\
$6)$ & No cavitation \\
$7)$ & Pleural indentation \\
8) & Accompanied by small nodules distributed \\
9) & along bronchovascular bundle \\
$10)$ & Beaded appearance \\
\hline
\end{tabular}

bronchogram (a beaded appearance), suggesting peripheral SCLC rather than a benign lesion. The initial diagnosis in all 5 cases was a benign lesion, so no recommendations were made for a PET-CT scan or fine-needle, aspiration biopsy. The interval between the earlier CT scan and that on which a correct diagnosis was based was 5 to 15 months. Follow-up CT was recommended at 12 months in cases 1 and 3 here in accordance with the standard guidelines, as these patients had a history of smoking and small nodules of less than $4-5 \mathrm{~mm}$ in size [6-8,10,11]. Rapid and aggressive progression is often observed in SCLC, which can show a volume doubling time of 29 days, so a 12-month delay in performing follow-up CT could be critical [12]. The average doubling time in the present cases was 71 days. It has been re- 
ported that small pulmonary nodules, even when malignant, are less aggressive than advanced lung cancer [10]. The results of the present study, however, show that a pulmonary nodule detected incidentally could be an aggressive tumor such as SCLC. This indicates that followup CT at shorter intervals, PET-CT, and fine-needle, aspiration biopsy should be performed in high-risk patients where initial images reveal a lesion with a beaded appearance.

The number of patients receiving a coronary CT scan has increased. Some risk factors for coronary artery disease such as age, male sex, and smoking are also risk factors for bronchial carcinoma. The growing number of cardiac CT scans has led to a steep increase in the identification of collateral findings. The rate of lung cancers detected as incidental findings at cardiac CT was $0.2 \%$ to 2.7\% [13-15]. In the present study, coronary CT revealed lesions with a beaded appearance in Cases 2 and 3, which should have indicated the need for further examination. According to a report by the National Comprehensive Cancer Network, CT screening for lung cancer reduced mortality by $20 \%$ and all-cause mortality by $7 \%$ [16]. Once the benefit of CT screening is recognized, the number of chest CTs will increase.

Few studies have investigated the characteristic CT findings of SCLC on the periphery of the lung. Kazawa et al. reviewed 68 SCLC cases and classified 8 types of extension and spread, one of which was peripheral and mediastinal, showing as a well-demarcated, subpleural tumor accompanied by small, daughter nodules distributed along the bronchovascular bundle [17]. Sone et al. reported a small, spindle-shaped or pyramidal lesion as a subtle CT finding of SCLC [18]. Hashimoto et al. reported peribronchial thickening adjacent to the primary tumor as one finding of SCLC originating in the lung parenchyma [19]. The findings of the present study revealed a solid nodule with pleural indentation and emphysematous change in the background but no air bronchogram or cavitation as characteristics other than those previously described.

Stage T1-2N0M0 disease is usually taken to indicate a surgical intervention in LD-SCLC [4,20]. In one study, multimodality treatment comprising surgery and adjuvant chemotherapy resulted in a 5-year survival rate of $59 \%$ in patients with T1N0M0 SCLC [3]. Another study confirmed that cure was possible in surgically-resected, LD-SCLC [10]. Patients with node-negative disease had best survival [21]. Median survival for SCLC presenting as a solitary pulmonary nodule was much better than that for LD-SCLC [22]. An earlier diagnosis would confer more treatment options, resulting in a better prognosis.

The main limitation of this retrospective study was the small sample size. Small-cell lung cancer is much less common than non-SCLC. Moreover, detecting SCLC at an early stage is much more difficult due to the speed at which the disease progresses. No pathological analyses were available for review in this study, as no surgical resection was performed. The objective of the present study was to identify the characteristic CT findings of very early-stage SCLC. Therefore, we were unable to draw any conclusions regarding the likelihood of lesions with these characteristics later becoming malignant or benign. In other words, the specificity of these findings requires further clarification. However, we do believe that they constitute useful and specific findings indicative of a diagnosis of early-stage SCLC.

\section{CONCLUSION}

To the best of our knowledge, this is the first study to identify a clear pattern of spread and characteristics, particularly beaded-pattern lesions, in images of early-stage SCLC. These results indicate the importance of being aware of the morphologic characteristics of very early stage SCLC in preventing diagnostic delay. We believe that these findings will help physicians and radiologists evaluate small pulmonary nodules.

\section{ACKNOWLEDGEMENTS}

We would like to thank Jeremy Williams, Tokyo Dental College, for his assistance with the English of the manuscript.

\section{REFERENCES}

[1] Shepherd, F. A., Ginsberg, R. J., Haddad, R., Feld, R., Sagman, U., Evans, W. K., DeBoer, G. and Maki, E. (1993) Importance of clinical staging in limited small-cell lung cancer: A valuable system to separate prognostic subgroups. Journal of Clinical Oncology, 11, 1592-1597.

[2] Lim, E., Belcher, E., Yap, Y. K., Nicholson, A. G. and Goldstraw, P. (2008) The role of surgery in the treatment of limited disease small cell lung cancer: Time to reevaluate. Journal of Thoracic Oncology, 3, 1267-1271. http://dx.doi.org/10.1097/JTO.0b013e318189a860

[3] Holmes, E. C. (1995) The role of surgery in small cell carcinoma of the lung (SCLC). Lung Cancer, 12, S17S21. http://dx.doi.org/10.1016/S0169-5002(10)80015-7

[4] Simon, G. R. and Wagner, H. (2003) Small cell lung cancer. Chest, 123, 259S-271S. http://dx.doi.org/10.1378/chest.123.1_suppl.259S

[5] Ost, D., Fein, A. M. and Feinsilver, S. H. (2003) The solitary pulmonary nodule. New England Journal of Medicine, 348, 2535-2542. http://dx.doi.org/10.1056/NEJMcp012290

[6] Libby, D. M., Smith, J. P., Altorki, N. K., Pasmantier, M. W., Yankelevitz, D. and Henschke, C. I. (2004) Managing the small pulmonary nodule discovered by CT. Chest, $\mathbf{1 2 5}$, 1522-1529. http://dx.doi.org/10.1378/chest.125.4.1522

[7] Piyavisetpat, N., Aquino, S. L., Hahn, P. F., Halpern, E. F. and Thrall, J. H. (2005). Small incidental pulmonary nod- 
ules: How useful is short-term interval CT follow-up? Journal of Thoracic Imaging, 20, 5-9. http://dx.doi.org/10.1097/01.rti.0000154076.06324.cf

[8] MacMahon, H., Austin, J. H. M., Gamsu, G., Herold, C. J., Jett, J. R., Naidich, D. P., Patz Jr., E.F. and Swensen, S. J. (2005) Guidelines for management of small pulmonary nodules detected on CT scans: A statement from the fleischner society. Radiology, 237, 395-400. http://dx.doi.org/10.1148/radiol.2372041887

[9] Winer-Muram, H. T. (2006) The solitary pulmonary nodule. Radiology, 239, 34-49. http://dx.doi.org/10.1148/radiol.2391050343

[10] Gould, M. K., Fletcher, J., Iannettoni, M. D., Lynch, W. R., Midthun, D. E., Naidich, D. P. and Ost, D. E. (2007) Evaluation of patients with pulmonary nodules: When is it lung cancer? ACCP evidence-based clinical practice guidelines (2nd Edition). Chest, 132, 108S-130S. http://dx.doi.org/10.1378/chest.07-1353

[11] Van't Westeinde, S. C., de Koning, H. J., Xu, D. M., Hoogsteden, H. C. and van Klaveren, R. J. (2008) How to deal with incidentally detected pulmonary nodules less than $10 \mathrm{~mm}$ in size on CT in a healthy person. Lung Cancer, 60, 151-159. http://dx.doi.org/10.1016/j.lungcan.2008.01.020

[12] Geddes, D. M. (1979) The natural history of lung cancer: A review based on rates of tumour growth. British Journal of Diseases of the Chest, 73, 1-17. http://dx.doi.org/10.1016/0007-0971(79)90002-0

[13] Onuma, Y., Tanabe, K., Nakazawa, G., Aoki, J., Nakajima, H., Ibukuro, K. and Hara, K. (2006) Noncardiac findings in cardiac imaging with multidetector computed tomography. Journal of the American College of Cardiology, 48, 402-406. http://dx.doi.org/10.1016/j.jacc.2006.04.071

[14] Haller, S., Kaiser, C., Buser, P., Bongartz, G. and Bremerich, J. (2006) Coronary artery imaging with contrastenhanced MDCT: Extracardiac findings. American Journal of Roentgenology, 187, 105-110. http://dx.doi.org/10.2214/AJR.04.1988

[15] Kim, T. J., Han, D. H., Jin, K. N. and Lee, K. W. (2010) Lung cancer detected at cardiac CT: Prevalence, clinicoradiologic features, and importance of full-field-ofview images. Radiology, 255, 369-376. http://dx.doi.org/10.1148/radiol.10091083

[16] Wood, D. E., Eapen, G. A., Ettinger, D. S., Hou, L., Jackman, D., Kazerooni, E., Klippenstein, D., Lackner, R.P., Leard, L., Leung, A.N.C., Massion, P.P., Meyers, B.F., Munden, R.F., Otterson, G.A., Peairs, K., Pipavath, S., Pratt-Pozo, C., Reddy, C., Reid, M.E., Rotter, A.J., Schabath, M.B., Sequist, L.V., Tong, B.C., Travis, W.D., Unger, M. and Yang, S. C. (2012) Lung cancer screening: Clinical practice guidelines in oncology. JNCCN Journal of the National Comprehensive Cancer Network, 10, 240 265.

[17] Kazawa, N., Kitaichi, M., Hiraoka, M., Togashi, K., Mio, N., Mishima, M. and Wada, H. (2006) Small cell lung carcinoma: Eight types of extension and spread on computed tomography. Journal of Computer Assisted Tomography, 30, 653-661. http://dx.doi.org/10.1097/00004728-200607000-00017

[18] Sone, S., Nakayama, T., Honda, T., Tsushima, K., Li, F., Haniuda, M., Takahashi, Y., Hanaoka, T., Takayama, F., Koizumi, T., Kubo, K., Yamada, T., Kondo, R., Fushimi, H. and Suzuki, T. (2007) CT findings of early-stage small cell lung cancer in a low-dose CT screening programme. Lung Cancer, 56, 207-215. http://dx.doi.org/10.1016/j.lungcan.2006.12.014

[19] Hashimoto, M., Heianna, J., Okane, K., Hirano, Y. and Watarai, J. (1999) Small cell carcinoma of the lung: CT findings of parenchymal lesions. Radiation MedicineMedical Imaging and Radiation Oncology, 17, 417-421.

[20] Deslauriers, J. (1997) Surgery for small cell lung cancer. Lung Cancer, 17, S91-S98. http://dx.doi.org/10.1016/S0169-5002(97)00642-9

[21] Karrer, K., Shields, T. W., Denck, H., Hrabar, B., VogtMoykopf, I. and Salzer, G. M. (1989). The importance of surgical and multimodality treatment for small cell bronchial carcinoma. Journal of Thoracic and Cardiovascular Surgery, 97, 168-176.

[22] Quoix, E., Fraser, R., Wolkove, N., Finkelstein, H. and Kreisman, H. (1990) Small cell lung cancer presenting as a solitary pulmonary nodule. Cancer, 66, 577-582. http://dx.doi.org/10.1002/1097-0142(19900801)66:3<577 ::AID-CNCR2820660328>3.0.CO;2-Y 